\title{
PENGEMBANGAN MEDIA E-LEARNING PADA MATA KULIAH KOMPUTASI I DI PERGURUAN TINGGI.
}

\author{
Achmad Buchori \\ Dosen Prodi Pendidikan Matematika IKIP PGRI Semarang \\ e-mail: buccherypgri@gmail.com
}

\begin{abstract}
Media Development E-Learning in Computing I course at the university.This study aims to acquire e-learning instructional media are valid for selfstudy student in the course of computing I. Population in the study were all students of third semester of mathematics education IKIP PGRI Semarang.

This study is a research and development. In media studies e-learning development is carried out with 4 (four) stages, namely (a) a preliminary analysis, (b) Design, (c) Evaluation, (d) Revised. Processing the data using descriptive qualitative data analysis techniques. Corresponding results of questionnaires about the development of e-learning in the obtained value sig $=0.00$ and $R=0,541$, which means it affects the motivation for $54.1 \%$ of the student learning outcomes. Gained an average of better learning outcomes between the experimental class at 84.27 compared with 80.05 for the control class.

The results obtained from the e-learning instructional media are valid for independent study students on computing courses I according to developmental theory Akker and student learning outcomes.
\end{abstract}

Keywords: Instructional media e-learning, Computational mathematics, Akker development theory.

ABSTRAK:Achmad Buchori (2012). Pengembangan Media E-Learning Pada Mata kuliah Komputasi I di Perguruan Tinggi.Penelitian ini bertujuan untuk memperoleh media pembelajaran e-learning yang valid untuk belajar mandiri mahasiswa pada mata kuliah komputasi I. Populasi dalam dalam penelitian ini adalah seluruh mahasiswa semester III pendidikan matematika IKIP PGRI Semarang.

Penelitian ini adalah penelitian pengembangan. Dalam penelitian pengembangan media e-learning ini dilakukan dengan 4 (empat) tahap yaitu (a) Analisis pendahuluan, (b) Perancangan, (c) Evaluasi, (d) Revisi. Pengolahan data dengan menggunakan teknik analisis data deskriptif kualitatif. Sesuai hasil angket tentang pengembangan media elearning di peroleh nilai sig $=0.00$ dan $R=0.541$, yang artinya motivasi mempengaruhi sebesar $54.1 \%$ terhadap hasil belajar mahasiswa. Diperoleh rata-rata hasil belajar yang lebih baik antara kelas eksperimen sebesar 84.27 dibandingkan dengan kelas kontrol sebesar 80.05.

Dari hasil tersebut diperoleh media pembelajaran e-learning yang valid untuk belajar mandiri mahasiswa pada mata kuliah komputasi I sesuai teori perkembangan Akker dan hasil belajar mahasiswa.

Kata kunci: Media pembelajaran e-learning, Komputasi matematik, Teori perkembangan Akker. 


\section{PENDAHULUAN}

\section{A. Latar Belakang}

Melihat kondisi pendidikan di Indonesia yang belum menunjukkan hasil yang signifikan menjadi keprihatinan kita semua sebagai warga indonesia. Ini dibuktikan dengan Indeks pembangunan pendidikan untuk semua atau education for all di Indonesia menurun. Jika tahun lalu Indonesia berada di peringkat ke-65, tahun ini merosot di peringkat ke-69, kemudian berdasarkan data dalam Education For All (EFA) Global Monitoring Report 2011: Di Balik Krisis: Konflik Militer dan Pendidikan yang dikeluarkan Organisasi Pendidikan, Ilmu Pengetahuan, dan Kebudayaan Perserikatan Bangsa-Bangsa (UNESCO) yang diluncurkan di New York, Amerika Serikat, Senin (1/3) waktu setempat, indeks pembangunan pendidikan (education development index/EDI) menurut data tahun 2008 adalah 0,934. Nilai ini menempatkan Indonesia di posisi ke-69 dari 127 negara di dunia. (Kompas, Kamis, 03 Maret 2011).

Kemudian, jika dilihat kondisi mahasiswa semester 3 prodi pendidikan matematika baik kelas regular dan RSBI mata kuliah Komputasi 1 masih cukup memperihatinkan, diantaranya kendalanya sebagai berikut: 1). Lemahnya kreatifitas mahasiswa dalam penggunaan IT dalam proses perkuliahan, dimana biasanya para dosen harus menerangkan ulang penggunaan media internet dalam menyajikan materi, agar materi lebih menarik dan menyenangkan. 2). Lemahnya kemampuan dasar mahasiswa dalam penggunaan komputer dalam pembelajaran matematika dengan melihat nilai rata-rata mid semester yaitu 68,25. 3). Mahasiswa kurang pelatihan tentang penggunaan media powerpoint dan Macromedia Flash yang nantinya hasilnya akan dimasukkan kedalam Website IKIP PGRI Semarang di menu E-learning.

Dikarenakan hal tersebut, perlu dilakukan suatu usaha untuk merancang materi pembelajaran khususnya mata kuliah komputasi I. Materi dirancang dengan mengembangkan materi yang telah ada dengan cara memodifikasinya. Sehubungan dengan hal itu, Heinich,et al (1996) 
menyatakan bahwa ada tiga alternatif untuk memperoleh materi pembelajaran, yang salah satunya adalah memodifikasi materi yang telah ada dimana alternatif ini merupakan prosedur yang lebih efisien, kreatif, dan menantang daripada merancang sendiri materi pembelajaran yang akan menghabiskan waktu dan biaya atau dengan menggunakan materi yang telah disediakan oleh perguruan tinggi. Agar materi tersebut menarik sehingga memotivasi mahasiswa belajar mandiri, maka materi dikembangkan menggunakan teknologi informasi komunikasi dengan menempatkan pada media website yang terkoneksi dengan internet yang mana manfaat media dapat diasosiasikan sebagai penarik perhatian dan membuat mahasiswa tetap terjaga dan memperhatikan (Kemp \& Dayton dalam Arsyad, 2003).

Berdasarkan uraian diatas, maka peneliti mengambil judul "Pengembangan Media E-learning pada Mata kuliah Komputasi I di Perguruan Tinggi”

\section{B. Rumusan Masalah}

Berdasarkan latar belakang diatas, maka rumusan penelitian adalah:

1. Bagaimana mengembangkan E-learning sehingga menghasilkan media pembelajaran komputasi I yang valid untuk mahasiswa belajar mandiri?

2. Bagaimana sikap mahasiswa terhadap pembelajaran komputasi I dengan media E-learning?

3. Bagaimana motivasi mahasiswa dalam mempelajari materi komputasi I secara mandiri dengan media E-learning?

4. Bagaimana hasil belajar mahasiswa dalam pembelajaran komputasi I yang menggunakan media E-learning?

\section{Tujuan Penelitian}

Dari permasalahan yang telah dirumuskan, maka penelitian ini bertujuan untuk :

1. Mengembangkan media E-learning pada mata kuliah komputasi I sedemikian hingga mahasiswa dapat belajar mandiri. 
2. Menghasilkan media E-learning pada mata kuliah komputasi I yang valid.

3. Mengetahui efektifitas media E-learning pada materi komputasi I yang dilihat dari kualitas hasil belajar dan sikap mahasiswa selama proses pembelajaran.

4. Mengetahui tingkat motivasi mahasiswa belajar mandiri terhadap materi pembelajaran komputasi I dengan media E-learning.

\section{Manfaat Penelitian}

Hasil penelitian ini ini diharapkan bermanfaat untuk :

1. Ilmu Pengetahuan dan Teknologi (IPTEK), sehingga dengan dikembangkannya materi pembelajaran matematika pada media Elearning dapat memberikan kontribusi pada dunia pendidikan.

2. Proses pembelajaran, sehingga kegiatan belajar mengajar dapat menjadi menarik dan menyenangkan dengan mempelajari matematika pada media E-learning.

3. Lembaga Pendidikan Tenaga Kependidikan (LPTK) yang diharapkan menggunakan informasi dari hasil uji coba penelitian ini untuk mengembangkan media website pada mata kuliah matematika yang lainnya.

4. Perguruan tinggi, sehingga dapat memaksimalkan fungsi laboratorium komputer, khususnya komputer yang telah terhubung dengan internet dalam memfasilitasi mahasiswa lebih belajar mandiri.

\section{METODE PENELITIAN}

\section{A. Jenis Penelitian}

Jenis penelitian ini adalah penelitian pengembangan dengan menggunakan teknik analisis data deskriptif kualitatif.

\section{B. Variabel Penelitian}

Variabel dalam penelitian ini adalah media pembelajaran komputasi yang dikembangkan pada E-learning dengan mata kuliah komputasi I yang meliputi isi (content) dan sistematika penyajiannya. 


\section{Subjek Penelitian}

Subjek dalam penelitian ini adalah media E-Learning pada materi kuliah Komputasi I dengan responden para mahasiswa semeester III sebanyak 2 kelas dari 8 kelas yang ada di Prodi Pendidikan Matematika IKIP PGRI Semarang.

\section{Prosedur Penelitian Pengembangan}

Adapun langkah-langkahnya yaitu sebagai berikut :

1. Tahap Analisis Pendahuluan

2. Tahap Perancangan

3. Tahap Evaluasi

4. Tahap Revisi

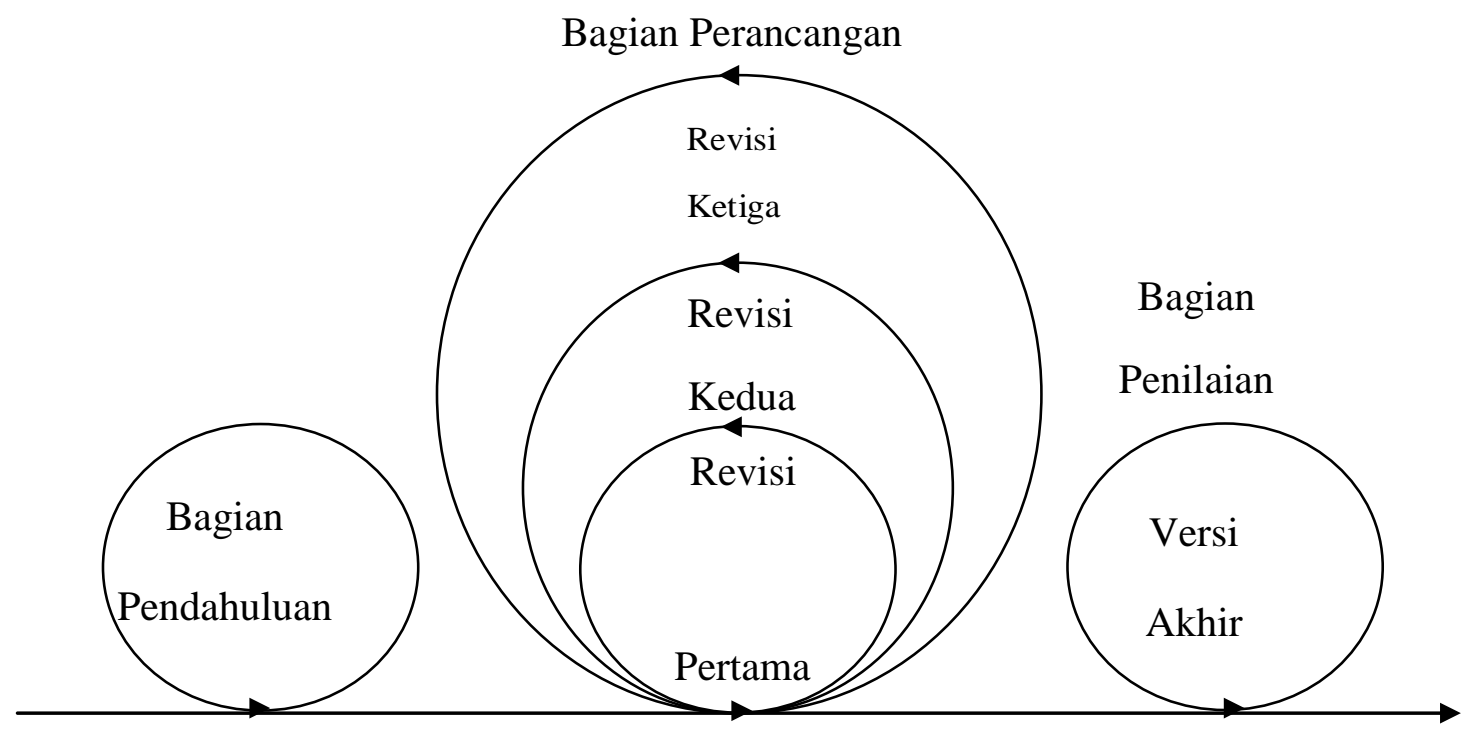

Gambar 2. Diagram Penelitian Pengembangan

\section{E. Teknik Pengumpulan Data}

1. Angket

Pada umumnya tujuan penggunaan angket atau kuesioner dalam proses pembelajaran terutama adalah untuk memperoleh data mengenai latar belakang mahasiswa sebagai salah satu bahan dalam menganalisis tingkah laku dan proses belajar mereka. Angket sering digunakan untuk menilai hasil belajar ranah afektif. Ia dapat berupa bentuk kuesioner 
bentuk pilihan ganda dan dapat pula berbentuk skala sikap. (Sudijono, 2005)

2. Observasi

Pada penelitian ini, observasi digunakan untuk mengumpulkan data mengenai tingkat motivasi mahasiswa dalam mempelajari secara mandiri materi pembelajaran pada media website. Observasi terhadap subjek penelitian dilakukan selama proses pembelajaran.

3. Tes Hasil Belajar

Bruce (dalam Djaali dan Muljono, 2004), mengatakan tes dapat digunakan untuk mengukur banyaknya pengetahuan yang diperoleh individu dari suatu bahan pelajaran yang terbatas pada tingkat tertentu. Pada penelitian ini, data tes diperoleh dari latihan soal, tugas pekerjaan rumah, dan tes yang diberikan pada akhir pembelajaran.

\section{F. Teknik Analisis Data}

1. Analisis Data Angket

Pada penelitian ini, untuk mengukur sikap mahasiswa digunakan angket tertutup yang dianalisis menggunakan skala Linkert. Dalam skala Linkert, pernyataan-pernyataan yang diajukan, baik pernyataan positif maupun negatif dinilai oleh responden dengan sangat setuju, setuju, tidak punya pendapat (netral), tidak setuju, dan sangat tidak setuju.

Pada penelitian ini, motivasi siswa diukur menggunakan angket tertutup pilihan ganda yang datanya dianalisis per butir pertanyaan. Hasil angket tersebut dirangkum dalam suatu tabel dan dideskripsikan secara persentase ( Nasoetion, 2007). Pada pertanyaan yang sifatnya terbuka, maka dianalisis dan disimpulkan secara umum.

2. Analisis Hasil Belajar

Data tes yang diperoleh dari hasil jawaban latihan soal, tugas pekerjaan rumah, dan tes diolah untuk menghasilkan nilai akhir yang kemudian dianalisis untuk mengetahui kategori hasil belajar mahasiswa. Nilai akhir tersebut diperoleh dengan jalan menjumlahkan nilai tugas 
pekerjaan rumah(T), nilai latihan (L), dan nilai tes/ujian (U), yang masing-masing diberi bobot 20, 30, dan 50, lalu dibagi 100. jika dituangkan dalam bentuk rumus, yaitu sebagai berikut :

$\mathrm{N}_{\mathrm{A}}=\frac{20(T)+30(L)+50(U)}{100}$

Keterangan: $\mathrm{N}_{\mathrm{A}}=$ Nilai akhir

$L \quad=$ Nilai Latihan

$T \quad=$ Nilai Tugas Pekerjaan Rumah

$U \quad=$ Nilai Tes/ Ujian

(Modifikasi dari Sudijono, 2005)

Tabel 4. Kategori Hasil Belajar Mahasiswa

\begin{tabular}{|c|c|}
\hline Nilai Akhir Siswa & Kategori \\
\hline $80-100$ & Baik Sekali \\
\hline $66-79$ & Baik \\
\hline $56-65$ & Cukup \\
\hline $40-55$ & Kurang \\
\hline $30-39$ & Gagal \\
\hline
\end{tabular}

(Arikunto, 1991)

\section{HASIL DAN PEMBAHASAN}

A. Pengembangan media e-learning dalam menghasilkan media pembelajaran komputasi I yang valid untuk belajar mandiri mahasiswa.

Dalam penelitian pengembangan media e-learning pada mata kuliah komputasi 1 semester 3 prodi pendidikan matematika IKIP PGRI Semarang, sesuai dengan teori perkembangan Akker (1999) ada 4 (empat) tahap yaitu:

1. Tahap Analisis Pendahuluan

Pada tahap ini, peneliti telah melakukan analisis materi kuliah Komputasi I yang disesuaikan dengan kompetensi dasarnya yang disesuaikan dengan kurikulum prodi pendidikan matematika, mengobservasi kondisi laboratorium prodi matematika yang dijadikan 
sebagai tempat penelitian, dan mempersiapkan prosedur kerjasama dengan LABKOM IKIP PGRI Semarang untuk mendukung terlaksananya penelitian ini.

\section{Tahap Perancangan}

Pada tahap ini, peneliti telah melakukan perancangan dan pengembangan materi pembelajaran pada media komputer berbasis E-Learning. Adapun langkah-langkah penyampaian materi pembelajarannya adalah sebagai berikut : informasi materi disertai animasi, pemberian contoh soal, latihan soal, dan kunci jawaban yang dibuat dengan macromedia flash dan camtasia studio dengan di upload di web komputasil.blogspot.com. Sebelum materi tersebut diujicobakan, terlebih dahulu materi pada media tersebut telah divalidasi sesuai dengan lembar validasi yang diisi oleh dosen pembimbing, pertimbangan dari dosen pengampu mata kuliah komputasi I, dan tenaga ahli (expert review) di bidang desain E-Learning yang di wakili oleh Ir. Agung handayanto, M.Kom sebagai kepala PUSKOM IKIP PGRI Semarang dan Wijayanto, ST., M.Kom sebagai dosen komputasi Prodi Pendidikan Fisika. Setelah direvisi sebanyak 2 kali oleh validator diperoleh hasil yang cukup baik dilihat dari segi tampilan dan content (isi) media e-learning telah memenuhi syarat untuk di gunakan sebagai media pembelajaran komputasi 1 .

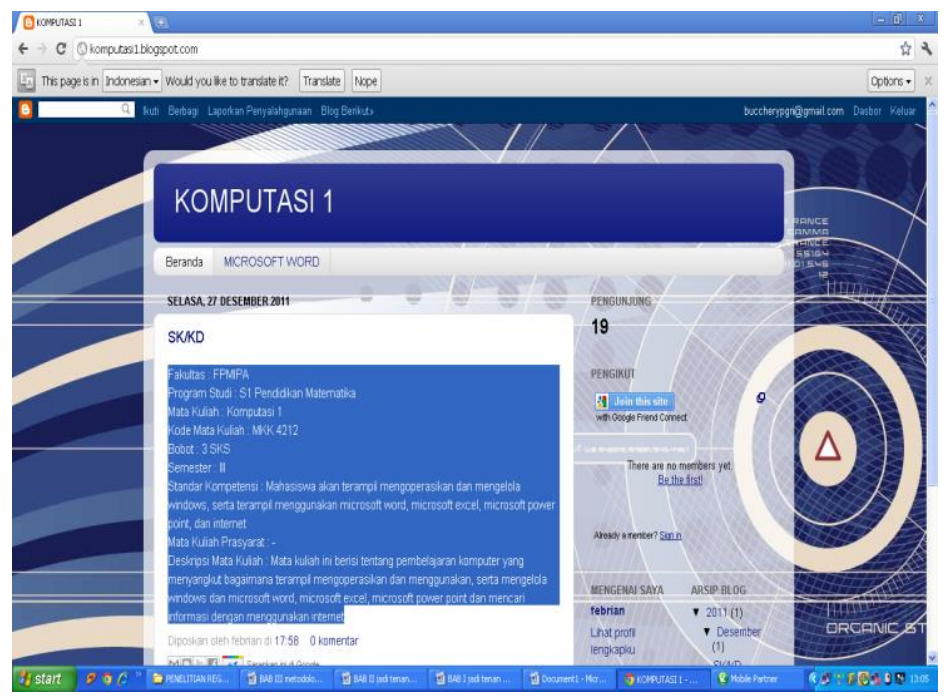

Gambar 1 
3. Tahap Evaluasi

Pada tahap ini, peneliti telah melakukan pengujian terhadap materi pembelajaran yang telah dikembangkan pada media komputer berbasis e-learning dengan cara melakukan kegiatan pembelajaran di Laboratorium komputer matematika yang mana mahasiswa berinteraksi langsung dengan komputer. Kemudian, peneliti mengobservasi kegiatan mereka selama proses pembelajaran. Pada akhir pertemuan, peneliti melakukan evaluasi kepada mahasiswa untuk mengetahui sejauh mana mereka dapat memahami pelajaran yang disampaikan menggunakan media komputer berbasis e-learning, dan mahasiswa diberikan angket untuk mengetahui sikap mereka terhadap pembelajaran komputasi I yang menggunakan media tersebut.

\section{Tahap Revisi}

Pada tahap ini, peneliti telah menganalisis hasil evaluasi yang telah dilakukan untuk dijadikan dasar dalam merevisi materi maupun media pembelajaran. Hasil dari tahap ini dianggap sebagai hasil akhir yang praktis dan valid sebagai media pembelajaran.

\section{B. Sikap dan motivasi mahasiswa terhadap pembelajaran komputasi I}

\section{dengan media e-learning.}

1. Hasil angket tentang implementasi media e-learning.

Dari hasil angket yang telah kita berikan kepada mahasiswa diperoleh hasil sebagai berikut:

Tabel 1 .

\begin{tabular}{|l|l|r|r|r|r|r|r|}
\hline NO. & \multicolumn{1}{|c|}{ Indikator } & SS & \multicolumn{1}{|c|}{ S } & \multicolumn{1}{|c|}{ C } & TS & STS & JML \\
\hline 1. & $\begin{array}{l}\text { Kejelasan tujuan pembelajaran } \\
\text { (rumusan, realistis) }\end{array}$ & 11 & 25 & 4 & 0 & 0 & 40 \\
\hline 2. & $\begin{array}{l}\text { Relevansi tujuan pembelajaran dengan } \\
\text { SK/KD/Kurikulum }\end{array}$ & 4 & 25 & 11 & 0 & 0 & 40 \\
\hline 3. & $\begin{array}{l}\text { Cakupan dan kedalaman tujuan } \\
\text { pembelajaran }\end{array}$ & 4 & 25 & 11 & 0 & 0 & 40 \\
\hline 4. & $\begin{array}{l}\text { Ketepatan penggunaan strategi } \\
\text { pembelajaran }\end{array}$ & 3 & 24 & 12 & 1 & 0 & 40 \\
\hline 5. & Interaktivitas & 5 & 19 & 15 & 1 & 0 & 40 \\
\hline
\end{tabular}




\begin{tabular}{|l|l|r|r|r|r|r|r|}
\hline 6. & Pemberian motivasi belajar & 4 & 15 & 16 & 5 & 0 & 40 \\
\hline 7. & Kontekstualitas dan aktualitas & 1 & 20 & 18 & 1 & 0 & 40 \\
\hline 8. & $\begin{array}{l}\text { Kelengkapan dan kualitas bahan } \\
\text { bantuan belajar }\end{array}$ & 5 & 14 & 19 & 2 & 0 & 40 \\
\hline 9. & $\begin{array}{l}\text { Kesesuaian materi dengan tujuan } \\
\text { pembelajaran }\end{array}$ & 10 & 26 & 4 & 0 & 0 & 40 \\
\hline 10. & Kedalaman materi & 3 & 20 & 16 & 1 & 0 & 40 \\
\hline 11. & Kemudahan untuk dipahami & 5 & 23 & 11 & 1 & 0 & 40 \\
\hline 12. & Sistematis, runut, alur logika jelas & 5 & 20 & 15 & 0 & 0 & 40 \\
\hline 13. & $\begin{array}{l}\text { Kejelasan uraian, pembahasan, contoh, } \\
\text { simulasi, latihan }\end{array}$ & 8 & 21 & 11 & 0 & 0 & 40 \\
\hline 14. & $\begin{array}{l}\text { Konsistensi evaluasi dengan tujuan } \\
\text { pembelajaran }\end{array}$ & 5 & 24 & 11 & 0 & 0 & 40 \\
\hline 15. & Ketepatan dan ketetapan alat evaluasi & 4 & 24 & 11 & 1 & 0 & 40 \\
\hline & Jumlah: & 77 & 325 & 185 & 13 & 0 & 600 \\
\hline
\end{tabular}

Dari hasil angket pada Tabel 1 diperoleh data kebanyakan lebih dari 50\% mahasiswa setuju atau puas terhadap penggunaan media e-learning dalam pembelajaran komputasi 1.

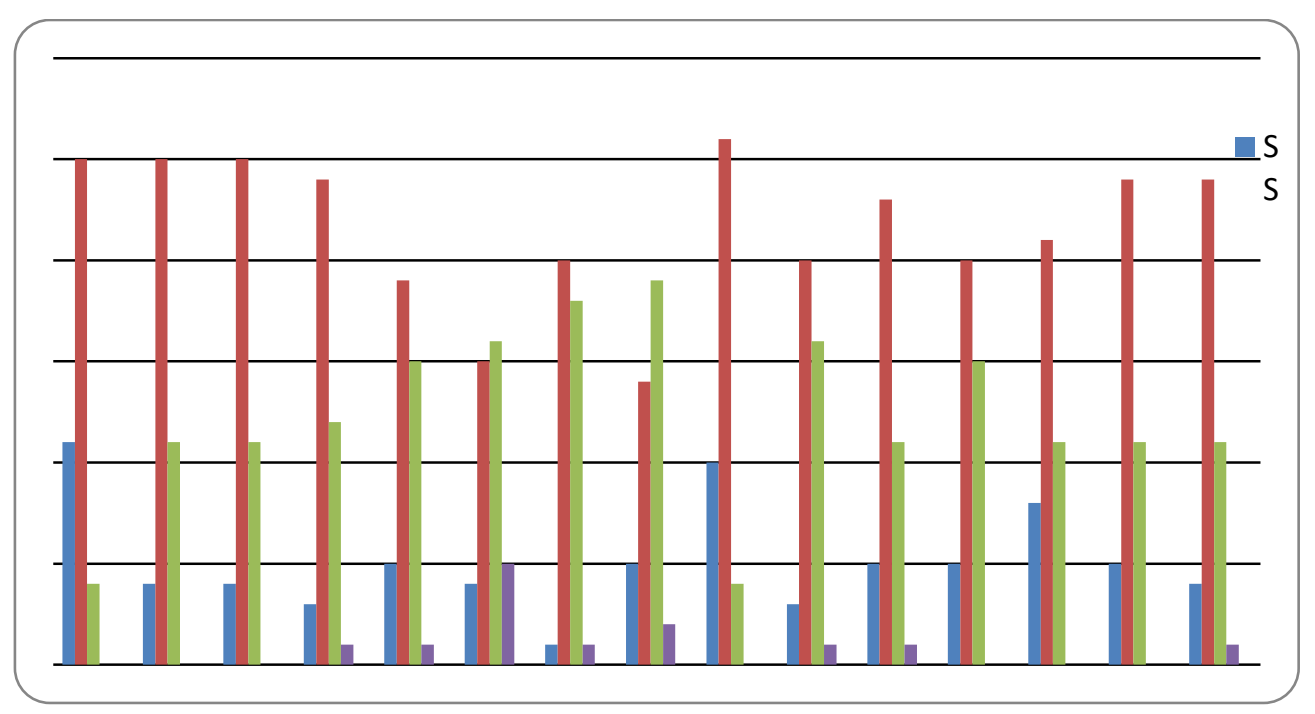

Gambar 1

Dari 15 indikator angket pembelajaran e-learning pada Gambar 1 diperoleh data bahwa mahasiswa sangat baik responnya pada indikator kesesuaian materi dengan tujuan pembelajaran, kejelasan tujuan pembelajaran, relevansi tujuan pembelajaran dan cakupan kedalaman tujuan pembelajaran. 


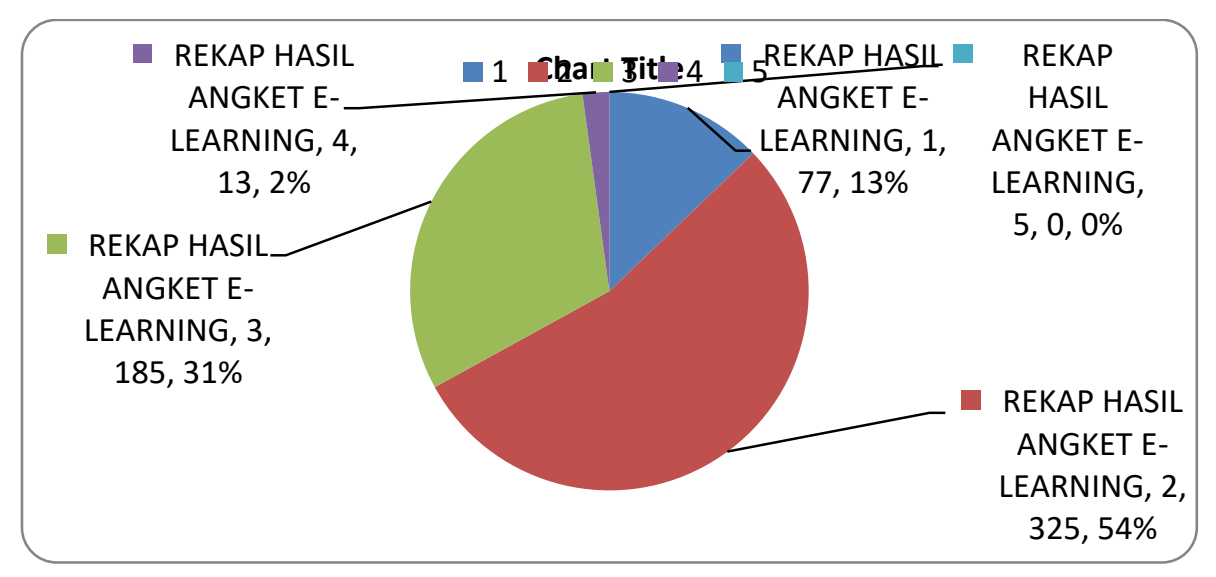

Gambar 2

Dari rekapitulasi hasil angket pada tabel 3 diperoleh 13\% mahasiswa kategori sangat setuju, 54\% mahasiswa kategori setuju, 31\% kategori cukup, 2\% kategori tidak setuju dan $0 \%$ kategori sangat tidak setuju.

Kemudian dari hasil olah SPSS versi 14 diperoleh nilai sig 0,00 artinya motivasi belajar mahasiswa dalam menggunakan media e-learning mempengaruhi hasil belajar mahasiswa, sesuai Tabel 2.

Tabel 2

\begin{tabular}{|l|l|r|r|r|r|l|}
\hline $\begin{array}{l}\text { Mode } \\
1\end{array}$ & & Sum of Squares & df & Mean Square & F & \multicolumn{1}{l|}{ Sig. } \\
\hline 1 & Regression & 37,035 & 1 & 37,035 & 15,719 &, $000(\mathrm{a})$ \\
& Residual & 89,529 & 38 & 2,356 & & \\
& Total & 126,564 & 39 & & & \\
\hline
\end{tabular}

a Predictors: (Constant), ANGKET

b Dependent Variable: EKS

Kemudian dari Tabel 3 diperoleh pada tabel $\mathrm{R}$ terlihat 0,541 artinya motivasi belajar mahasiswa menggunakan media e-learning mempengaruhi hasil belajar sebesar $54,1 \%$.

Tabel. 3. Model Summary

\begin{tabular}{|l|r|r|r|r|}
\hline $\begin{array}{l}\text { Mode } \\
1\end{array}$ & $\mathrm{R}$ & R Square & $\begin{array}{r}\text { Adjusted } \\
\text { R Square }\end{array}$ & $\begin{array}{c}\text { Std. Error } \\
\text { of the } \\
\text { Estimate }\end{array}$ \\
\hline 1 &, $541(\mathrm{a})$ &, 293 &, 274 & 1,53494 \\
\hline
\end{tabular}

a Predictors: (Constant), ANGKET 


\section{Hasil belajar mahasiswa dalam pembelajaran komputasi I yang menggunakan media E-learning.}

Tabel. 4

\section{One-Sample Test}

\begin{tabular}{|c|c|c|c|c|c|c|}
\hline & \multicolumn{6}{|c|}{ Test Value $=0$} \\
\hline & \multirow[b]{2}{*}{$\mathrm{t}$} & \multirow[b]{2}{*}{$\mathrm{df}$} & \multirow[b]{2}{*}{ Sig. (2-tailed) } & \multirow{2}{*}{$\begin{array}{c}\text { Mean } \\
\text { Difference }\end{array}$} & \multicolumn{2}{|c|}{$\begin{array}{l}95 \% \text { Confidence } \\
\text { Interval of the } \\
\text { Difference }\end{array}$} \\
\hline & & & & & Lower & Upper \\
\hline eksperimen & 295,886 & 39 &, 000 & 84,27875 & 83,7026 & 84,8549 \\
\hline kontrol & 111,659 & 39 & ,000 & 80,05500 & 78,6048 & 81,5052 \\
\hline
\end{tabular}

Dilihat dari Tabel 4 terlihat jelas bahwa kemampuan akademik kelas eksperimen (kelas 2A) kategori baik, dengan rata-rata $=84,27$ sedangkan kelas kontrol (kelas 2B) kategori baik juga dengan rata-rata $=80,05$.artinya ada perbedaan rata-rata hasil belajar yang kurang signifikan sebesar 4,22 saja dikarenakan materi komputasi I sudah diajarkan dibangku SMA.

\section{KESIMPULAN DAN SARAN}

\section{A. Kesimpulan}

Dari penelitian pengembangan e-learning selama kurang lebih 1(satu) semester ini, di dapatkan 3 hal meliputi:

1. Diperoleh media pembelajaran e-learning yang valid untuk belajar mandiri mahasiswa pada mata kuliah komputasi I sesuai teori perkembangan Akker .

2. Sesuai hasil angket tentang pengembangan media e-learning di peroleh nilai sig $=0.00$ dan $R=0.541$, yang artinya motivasi mempengaruhi sebesar $54.1 \%$ terhadap hasil belajar mahasiswa.

3. Diperoleh rata-rata hasil belajar yang kurang signifikan antara kelas eksperimen sebesar 84.27 dibandingkan dengan kelas kontrol sebesar 80.05 dikarenakan materi komputasi I telah diajarkan dibangku SMA. 


\section{B. Saran}

1. Perlu segera dilakukan penelitian lanjutan tentang penggunaan media e-learning di semua program studi di IKIP PGRI Semarang agar menghasilkan media yang lebih baik.

2. Sebaiknya perlu di kembangkan media mobile learning sesuai dengan tuntutan perkembangan zaman.

\section{DAFTAR PUSTAKA}

Alami, F. (2005). Pembuatan Media Pembelajaran dengan Macromedia Flash MX 2004. Jurusan Teknik Sipil Universitas Lampung. (www.unila.ac.id/ ftsipil/Tutorial /Manual\%20 Flash\%202004.pdf diakses tanggal 24 oktober 2011).

Arikunto, S. (1991). Dasar-Dasar Evaluasi Pendidikan. Bumi Aksara, Jakarta.

Arsyad, A. (2003). Media Pembelajaran. Raja Grafindo Persada, Jakarta.

Heinich, Molenda, Russell, and Smaldino. (1999). Instructional Media and Technologies for Learning. Prentice-Hall, Inc. Upper Saddle River, New Jersey.

Nasoetion, N. (2007). Evaluasi Pembelajaran Matematika. Jakarta : Universitas Terbuka.

Triluqman B S, H. (2007). E-learning Berbasis Web sebagai Bahan Belajar Mandiri. (http://heritl.blogspot.com/2007/07/e-learning-berbasis-websebagai-bahan.html

diakses tanggal 07 Maret 2011).

Yunan Y, I. (2006). Komputer untuk Pembelajaran Matematika. (http://www.Suaramerdeka. com/harian/0604/03/ragam03.htm diakses tanggal 06 Desember 2011). 